\title{
Ionospheric correction for spaceborne single-frequency GPS based on single layer model
}

\author{
Xia Yang*, Jiancheng Li and Shoujian Zhang \\ School of Geodesy and Geomatics, Wuhan University, Wuhan 430 079, China. \\ *Corresponding author. e-mail: yx-02@126.com
}

A modified ionospheric correction method and the corresponding approximate algorithm for spaceborne single-frequency Global Positioning System (GPS) users are proposed in this study. Single Layer Model (SLM) mapping function for spaceborne GPS was analyzed. SLM mapping functions at different altitudes were calculated. Ionospheric Pierce Point (IPP) trajectories of the dlft station (an IGS station located at the longitude of $4^{\circ} 23^{\prime} 15.22^{\prime \prime} \mathrm{E}$ and the latitude of $51^{\circ} 59^{\prime} 9.63^{\prime \prime} \mathrm{N}$, in the TU Delft University, The Netherlands) and the GRACE satellite were computed with the corresponding single layer height of 350 and $500 \mathrm{~km}$, respectively. The Klobuchar model was used to compute ionospheric delays for the dlft station, and modified Klobuchar model, together with scale factors, was used to compute the fractional ionospheric corrections above the GRACE altitudes. Calculation results were validated using dual-frequency observations. The study shows that the single layer height needs to be changed from 350 to $500 \mathrm{~km}$ according to the altitude of GRACE. Approximate forms of Earth angle and slant factor developed for modified Klobuchar model are applicable to GRACE, with accuracy adequate to preserve the essential elements required to compute ionospheric delays. Results show that the Klobuchar model is effective for ground GPS, and the modified Klobuchar model corrects more than $80 \%$ on average of the ionospheric delays for spaceborne single-frequency GPS.

\section{Introduction}

Since the first effort on using spaceborne GPS (Yunck et al. 1994), more and more spacecrafts are equipped with Global Positioning System (GPS) receivers, providing a well-accepted method for spacecraft navigation. Gravity Recovery and Climate Experiment (GRACE) is a typical low earth orbit (LEO) satellite system with GPS receiver onboard.

Ionospheric delay is the major error source affecting positioning precision and accuracy for GPS users, especially for single-frequency users.
Thus, users must find ways to eliminate the effects. Generally, dual-frequency users can form the ionosphere-free combinations to eliminate ionospheric delays effectively (Kroes 2006; Xu 2007). Single-frequency users should make use of ionospheric models to eliminate ionospheric delays. Many ionospheric models have been developed, including empirical models, physics-based models, etc. The Bent model (Bent et al. 1972a, b) and International Reference Ionosphere (IRI) model (Rawer et al. 1978; Bilitza 1986, 2001; Bilitza and Reinisch 2008; Bilitza et al. 2011) are empirical models, which have been derived based on years

Keywords. Ionospheric correction; single layer model (SLM); mapping function; single-frequency GPS; Klobuchar model; GRACE. 
and years of ionospheric measurements across the world, and can be used to estimate ionospheric density profiles at any place and time. The Parameterized Ionospheric Model (PIM) (Daniell et al. 1995) is a global ionospheric model based on theoretical climatology in the form of diurnally reproducible runs of a set of physics based, numerical ionospheric models. Sheffield University Plasmasphere Ionosphere Model (SuPIM) and SAMI are physics based models, too. These physical models are more useful than empirical models for users who have the need to simulate the performance of an operational system under representative conditions. In addition, the Klobuchar model (Klobuchar 1975, 1986, 1987; Li et al. 2009; Angrisano et al. 2011) is algorithm based and the GIM model (Schaer et al. 1998; Schaer 1999) is data based. The Klobuchar model was originally developed to estimate the ionospheric range delay for single-frequency GPS users, using only eight coefficients to represent the global ionosphere. These coefficients were derived from the Bent model as functions of time of year and solar activity. This model performs well with calculation simplicity and a root mean square (RMS) error of about $50 \%$.

However, all these models were developed for ground GPS originally and cannot be used for spaceborne GPS directly (Zhao 2003). One prerequisite for the above ionospheric models is the mapping function through which Slant Total Electronic Content (STEC) values are converted to Vertical Total Electronic Content (VTEC) values. The SLM mapping function is widely used because of its simplicity (Komjathy and Langley 1996; Mannucci et al. 1998; Schaer 1999; Orús et al. 2002; Wen et al. 2010). All ground stations are below the single layer at an altitude of $350 \mathrm{~km}$ (Klobuchar 1987) or $450 \mathrm{~km}$ (IGS 2006), while GRACE satellites are above it with an altitude of about $500 \mathrm{~km}$ at launch time that decreases as time goes by. Thus, single layer altitude needs to be adjusted to a higher position (Montenbruck and Gill 2002; Zhao 2003).

Single-frequency receivers are simple and low cost, and can be equipped on spacecrafts especially on formation flying satellites (i.e., multiple satellites working together in a group to accomplish the objective of one larger, usually more expensive, satellite), which generally require centimetrelevel accuracy of relative positioning to achieve the scientific goals. Spacecraft equipped with single-frequency GPS receiver, will have to use ionospheric models to mitigate ionosphere delays. However, with only one frequency, the efficiency of the ionospheric model cannot be validated. GRACE satellites are equipped with dual-frequency GPS receivers; therefore, the ionospheric model for a single-frequency receiver can be validated by dual-frequency observations.
Furthermore, some users use double difference (DD) combinations of L1 instead of ionospherefree combinations in order to preserve the integer nature of DD cycle ambiguities (Tancredi et al. 2011). Previous studies show that filtering double difference (DD) carrier-phase observables with fixed ambiguities allow determining the satellite relative position with high accuracy (Ebinuma et al. 2003; Leung and Montenbruck 2005). Ionospheric delays are almost eliminated by DD operation for sufficiently short baselines, because of the strong correlation. However, only part of the ionospheric delays can be eliminated by DD operation for medium and long baselines, and residuals can be as much as several carrier wavelengths (Tancredi et al. 2011). Thus, suitable ionospheric delay models are useful for both single-frequency and dual-frequency users. For real-time navigation, these models have to be as simple as possible, while being capable of describing the ionospheric delay with accuracy adequate to fix the DD integer ambiguities (Tancredi et al. 2011).

After years of observation and verification, the Klobuchar model is widely regarded as a convenient, practical, and reliable method of calculating the ionospheric corrections for single-frequency ground GPS users. Many further studies have been conducted on the Klobuchar model to improve the correction accuracy (Yuan et al. 2008; Li et al. 2009; Angrisano et al. 2011), and some study has been done to adapt the Klobuchar model for spaceborne users. Zhao et al. (2003) studied the ionospheric error simulation for both ground and space users using the Klobuchar model according to the ionospheric effects on the users at different altitudes. However, the ionospheric error simulation method need the electron density data at different heights, which are not easy to be obtained. Montenbruck and Gill (2002) studied an ionospheric correction technique for GPS tracking of LEO satellites, and assessed it by comparing with flight data from the Champ satellite that orbits the Earth at an altitude of $450 \mathrm{~km}$. However, further studies need to be done on the Klobuchar model for GPS onboard GRACE.

SLM mapping functions for single-frequency GPS users are introduced in this paper, including the selection of a single layer height and calculation of IPP trajectories for both ground and spaceborne GPS users. The Klobuchar model for ground users is introduced, and the modified Klobuchar model for spaceborne users is analyzed. New approximate forms of Earth angle and slant factor are proposed for spaceborne users. Ionospheric delays for GRACE are calculated using the modified Klobuchar model and scale factors. Effectiveness of the modified Klobuchar model is validated using dual-frequency observations. 


\section{SLM mapping function}

\subsection{SLM mapping function for ground users}

The concept of the ionospheric single layer model (SLM) is usually used in ionosphere research, i.e., the assumption that all the free electrons are concentrated in a shell of infinitesimal thickness. The line of sight between the receiver and the satellite intersects with the thin layer at the ionospheric pierce point (IPP), and the corresponding projection on the Earth is called sub-ionospheric point (figure 1). Ionospheric delay on the propagation path of the satellite and receiver is converted to the vertical direction of the IPP by means of the mapping function. The mapping function is defined as the ratio of propagation path ionospheric delay to the vertical ionospheric delay of IPP.

$$
\mathrm{MF}=\mathrm{STEC} / \mathrm{VTEC}
$$

where STEC is the propagation path ionospheric delay and VTEC is the vertical ionospheric delay of IPP.

A number of mapping functions are developed based on the single layer model, among which the trigonometric function is the simplest and most widely used. The SLM mapping function $F_{I}$ may also be written as (Dach et al. 2007):

$$
F_{I}(z)=\frac{E}{E_{v}}=\frac{1}{\cos z^{\prime}}
$$

with

$$
\sin z^{\prime}=\frac{R}{R+H} \sin z
$$

where $E$ and $E_{v}$ are the line-of-sight TEC values and vertical TEC values, respectively; $z$ and $z^{\prime}$ are the zenith angles at the height of the station and the single layer, respectively; $R$ is the mean radius

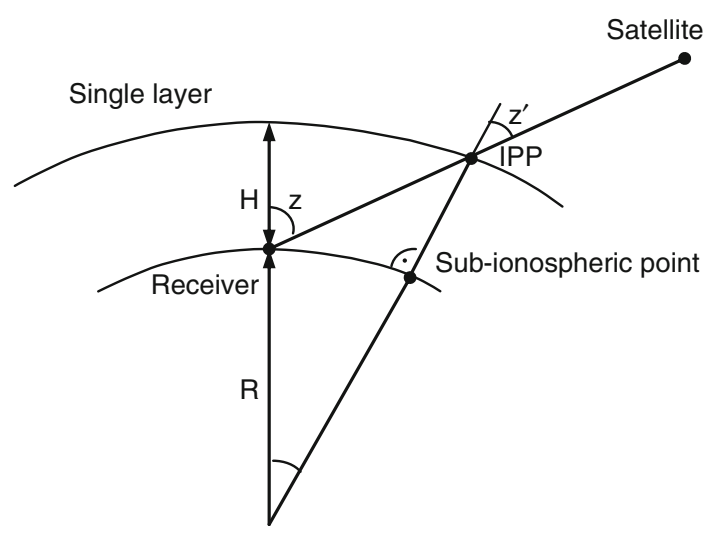

Figure 1. Single layer model for ground users. of the Earth (considered to be a sphere); $H$ is the height of the single layer above the Earth.

With the help of figure 1 , it can be easily verified that the Earth-centred angle equals $z-z^{\prime}$. The height of the SLM is supposed to be the height of maximum electron density, i.e., $350 \mathrm{~km}$. Moreover, the electron density is assumed to be a function of geographic or geomagnetic latitude and sun-fixed longitude. The modified SLM (MSLM) mapping function includes an additional constant, $\alpha$ (Schaer 1999):

$$
F_{I}(z)=\frac{E}{E_{v}}=\frac{1}{\cos z^{\prime}}
$$

with

$$
\sin z^{\prime}=\frac{R}{R+H} \sin (\alpha z) .
$$

The SLM and MSLM mapping functions vary with the single layer height. Positions of IPPs for ground users can be computed using SLM or MSLM. For example, the IPPs of dlft station were calculated as shown in figure 2 :

\subsection{SLM mapping function for spaceborne users}

The height of the F2 layer is about $200-600 \mathrm{~km}$. In the original Klobuchar model, the height of the single layer is supposed to be $350 \mathrm{~km}$, which is suitable for ground users. However, the altitudes of many spacecrafts such as GRACE are generally higher than $350 \mathrm{~km}$. Therefore, the $350 \mathrm{~km}$ altitude is no longer suitable for spaceborne GPS, and a higher single layer altitude needs to be chosen, as shown in figure 3.

We computed mapping function (figure 4a) and modified mapping function at heights of 250, 350, 450 or $500 \mathrm{~km}$, and calculated differences between the modified and original mapping function at different heights (figure 4b).

As shown in figure 4(a), the mapping function values are dependent on the elevation angles. The

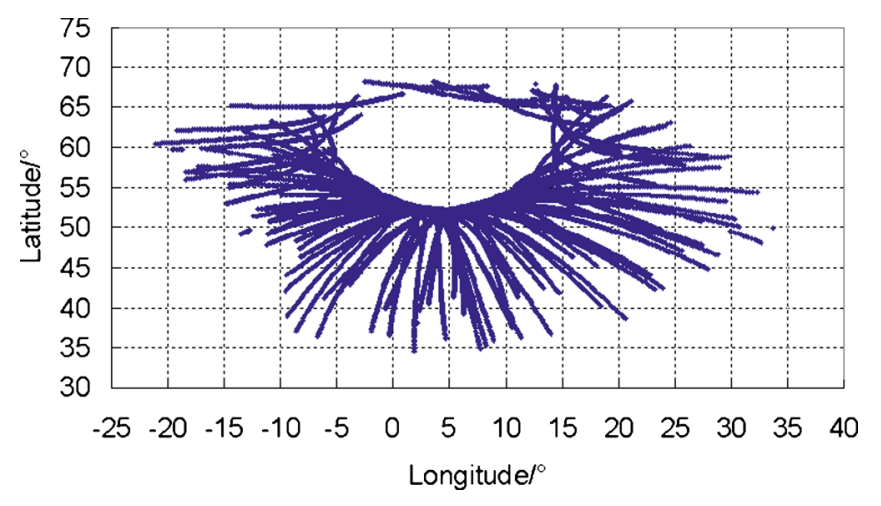

Figure 2. IPP trajectories for dlft station on 1 September 2010 . 


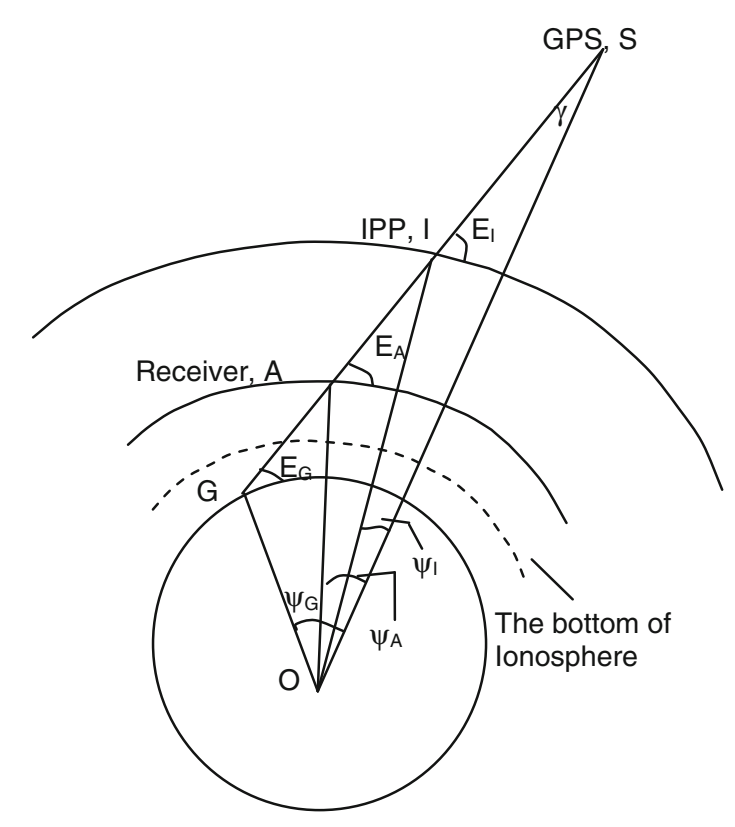

Figure 3. Single layer model for spaceborne users.

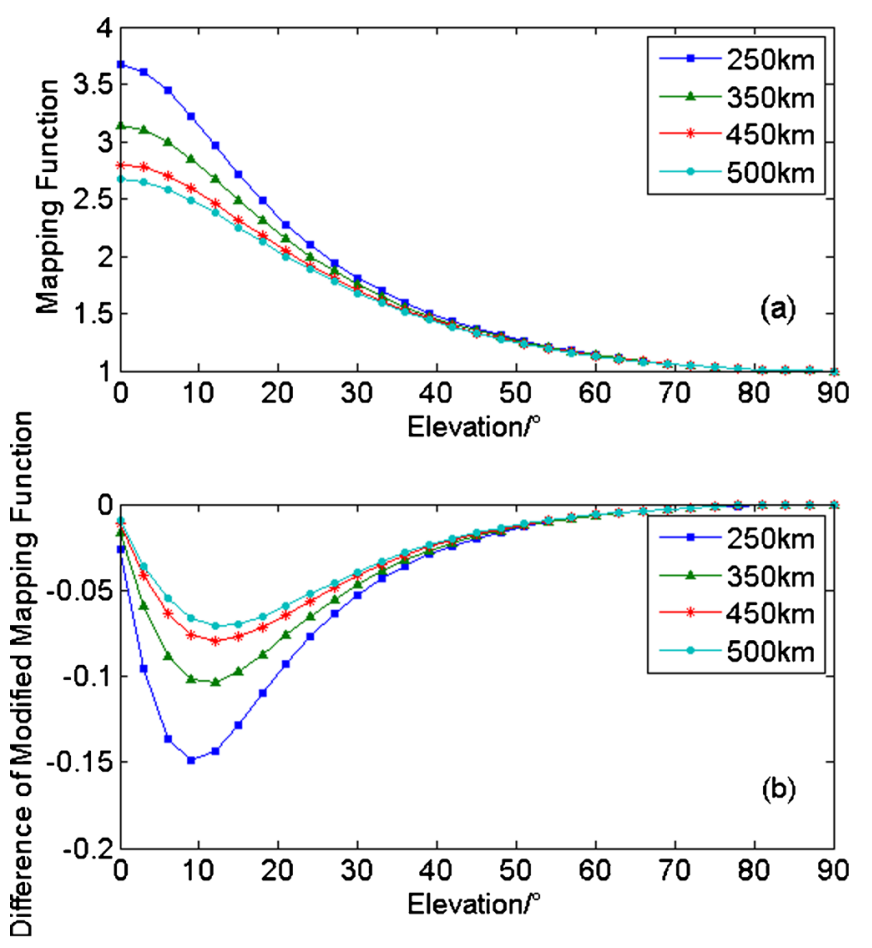

Figure 4. Mapping function at different single layer height (top panel) and difference between MSLM and SLM mapping function (MSLM mapping function minus SLM mapping function) (bottom panel).

maximum value of the mapping function varies from 3.67 to 2.67 , corresponding to the single layer height from 250 to $500 \mathrm{~km}$. The minimum value of the mapping function is 1.0. The difference between mapping functions at different altitudes varies significantly below $30^{\circ}$ and not much above $30^{\circ}$ elevation. Thus, ionospheric corrections will differ greatly for GPS satellites below $30^{\circ}$ if different single layer heights are used. Further calculations show that the difference of mapping functions at $30^{\circ}$ elevation can be up to 0.13 . That means a $0.13 \mathrm{~m}$ variation of path ionospheric delay corresponding to $1 \mathrm{~m}$ of vertical ionospheric delay, cannot be ignored. This variation will be as large as $0.68 \mathrm{~m}$ at $10^{\circ}$ elevation. Moreover, modified mapping function is less than mapping function (figure $4 \mathrm{~b}$ ) because of the coefficient $\alpha$. The difference between modified mapping function and mapping function varies significantly below $30^{\circ}$. Similarly, there is a $0.12 \mathrm{~m}$ variation of path ionospheric delay corresponding to $1 \mathrm{~m}$ of vertical ionospheric delay at $30^{\circ}$ elevation. Generally, the influence of single layer height on ionospheric corrections will be relatively high for low GPS satellites. This can be resolved by choosing a high elevation cut-off angle for ground users, since the observed GPS satellites are enough. However, the observed GPS satellites are not so much for spaceborne users compared to ground users, and the cut-off angle should not be chosen as great as $30^{\circ}$. Moreover, for doubledifference applications, the mutual observed GPS satellites are fewer. Thus, the single layer height needs to be chosen carefully for spaceborne users.

As mentioned before, altitudes of many spacecrafts are higher than $350 \mathrm{~km}$, thus a height of $350 \mathrm{~km}$ is meaningless for the spacecraft users. We now consider GRACE as an example. GRACE satellites were injected into a $500 \mathrm{~km}$ altitude, near circular polar orbit on 17 March 2002. Since then, the satellite orbit and its ground-track have been allowed to drift naturally. The mean semi-major axis for GRACE-B is shown in figure 5 (GRACE Orbital Configuration 2010).

As shown in figure 5, the highest altitude of GRACE is about $500 \mathrm{~km}$ above the Earth, whose mean radius is $6371 \mathrm{~km}$. The mean semi-major axis for GRACE B has changed from about 500-450 km from 2002 to 2012, and will be lower as time goes by. The datasets are chosen on day 244 of 2010 , and the mean altitude is about $470 \mathrm{~km}$ (changing periodically from 457 to $484 \mathrm{~km}$ during this day). The single layer should not be below the receiver altitude. Moreover, it should be as close as possible to the height of maximum electron density, i.e., $350 \mathrm{~km}$. Thus, we choose $500 \mathrm{~km}$ as the height of the single layer when dealing with ionospheric delays for GRACE, as the altitude of GRACE is no more than $500 \mathrm{~km}$. Positions of IPPs for onboard GPS users can be calculated using the MSLM. For example, the IPPs of GRACE B were calculated as shown in figure 6 . The IPPs of GRACE is not similar to the IPPs of ground station, since the position of GRACE is changing all the time. Thus, the IPPs are dependent on the trajectory of GRACE. 


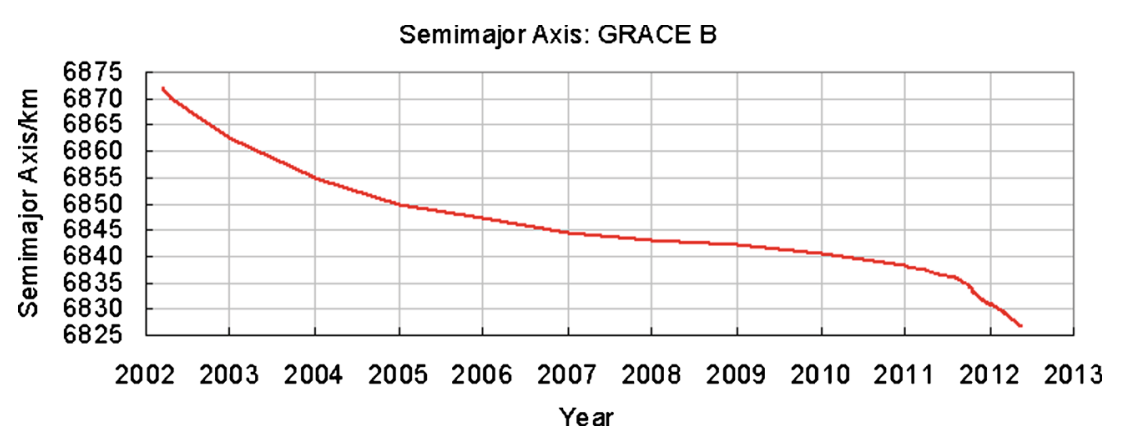

Figure 5. Semimajor axis of GRACE B.

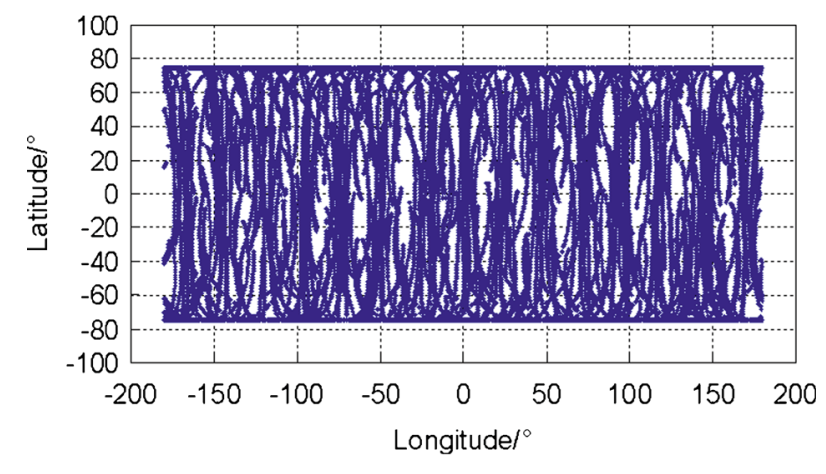

Figure 6. IPP trajectories for GRACE B on 1 September 2010.

\section{Ionospheric correction for spaceborne users}

\subsection{Ionospheric effects on GPS signals}

Ignoring the higher-order ionospheric effects, the ionospheric delays on code (from GPS satellite to receiver) can be expressed as a linear function of the total electron content (TEC) (Klobuchar 1996):

$$
I_{A}^{S}=\frac{40.3}{f^{2}} \times \operatorname{TEC}_{A}^{S}
$$

where $f$ is the carrier frequency in Hz. Magnitude of ionospheric delays on carrier phase is the same as on code, while the sign is opposite. The TEC is usually replaced by a function of VTEC and slant factor. Slant factor is the ratio of the TEC to the VTEC (Klobuchar 1987):

$$
I_{A}^{S}=\frac{40.3}{f^{2} \times \sin E_{I}} \times \mathrm{VTEC}_{A}
$$

where $E_{I}$ denotes the elevation at the IPP; $\operatorname{VTEC}_{A}$ can be expressed as:

$$
\mathrm{VTEC}_{A}=\int_{h_{A}}^{h_{S}} n_{e} d h
$$

where $h_{A}$ denotes the altitude of the receiver; $h_{S}$ denotes the altitude of the satellite; $n_{e}$ stands for the electron density.

As described in section 2, the altitudes of spacecrafts are generally higher than the bottom of the ionosphere (figure 3), and not the entire ionosphere affects the signal. A modified model is proposed as (Zhao et al. 2003):

$$
\begin{aligned}
I_{A}^{S} & =I_{G}^{S}-\frac{40.3}{f^{2} \cdot \sin E_{I}} \times \int_{h_{b}}^{h_{A}} n_{e} d h \\
& =\frac{40.3}{f^{2} \cdot \sin E_{I}} \times\left(\int_{h_{b}}^{h_{S}} n_{e} d h-\int_{h_{b}}^{h_{A}} n_{e} d h\right)
\end{aligned}
$$

where $I_{G}^{S}$ denotes the ionospheric delay at point $G$ which is illustrated in figure 3 and $h_{b}$ is the altitude of the ionosphere bottom.

Ionospheric delays can be calculated using equation (7) if users obtain the exact electron density from the ionosphere bottom to the spacecraft altitude, which is hard to obtain. Thus, application of equation (7) needs to be further studied.

Montenbruck and Gill (2002) computed the path delay caused by the fractional total electron content (TEC) above the receiver altitude by using the global TEC maps of the International GPS Service network and an altitude dependent scale factor. The scale factor can be predicted from the assumption of a Chapman profile for the altitude variation of the electron density or adjusted as a free parameter in the processing of an extended set of single frequency measurements. The formula of the scale factor can be expressed as follows:

$$
\alpha=\frac{\mathrm{TEC}_{\mathrm{IP}}}{\mathrm{TEC}_{0}}=\frac{e-\exp \left[1-\exp \left(-z_{\mathrm{IP}}\right)\right]}{e-\exp \left[1-\exp \left(h_{0} / H\right)\right]}
$$

where $\mathrm{TEC}_{\mathrm{IP}}$ is the total electron content of the ionosphere above IPP altitude, $\mathrm{TEC}_{0}$ is the total electron content above ground, $h_{0}$ is the inflection point height of a Chapman profile, $H$ is the scale height, $e>2.71828$ and $z_{\mathrm{IP}}=\left(h_{\mathrm{IP}}-h_{0}\right) / H$. 


\subsection{Klobuchar model for ground users}

In the Klobuchar model, VTEC value is calculated according to the latitude and longitude information at a specified point. Ionospheric delay during the night is considered as a constant, and ionospheric delay during the daytime is simulated using the positive part of the cosine function (Klobuchar 1975). Parameters are set to consider changes in the amplitude and period, reflecting the basic large-scale change of the ionosphere.

The ionospheric time delay can be calculated as follows (Klobuchar 1987):

$T_{\mathrm{IONO}}=F \times\left[5 \times 10^{-9}+\sum_{n=0}^{3} \alpha_{n} \Phi_{m}^{n} \times\left(1-\frac{x^{2}}{2}+\frac{x^{4}}{24}\right)\right]$

where

$$
x=\frac{2 \pi(t-50400)}{\sum_{n=0}^{3} \beta_{n} \Phi_{m}^{n}} ;
$$

$F$ stands for the slant factor; $\Phi_{m}$ stands for the geomagnetic latitude of IPP (unit: $\pi$ ); $\alpha_{n}$ and $\beta_{n}$ are transmitted as part of the satellite message; $t$ is local time of the IPP.

The users on the ground surface can utilize Klobuchar model with corresponding parameters broadcast in GPS navigation message to correct ionospheric delays directly. Some approximate forms are used in order to simplify the calculation process (Klobuchar 1987). We used these approximate equations to calculate the ionospheric delays for dlft station on 1 September 2010 (figure 7), while the selected visible satellites were used to form double difference (DD) observations with another station. Eight coefficients broadcast by
GPS in the navigation message on 1 September 2010 were used in this paper. The eight coefficients are as follows:

$\begin{array}{ll}\alpha_{0}=0.6519 \times 10^{-8}, & \alpha_{1}=0.1490 \times 10^{-7}, \\ \alpha_{2}=-0.5960 \times 10^{-7}, & \alpha_{3}=-0.1192 \times 10^{-6}, \\ \beta_{0}=0.7782 \times 10^{5}, & \beta_{1}=0.3277 \times 10^{5}, \\ \beta_{2}=-0.6554 \times 10^{5}, & \beta_{3}=-0.1966 \times 10^{6} .\end{array}$

As shown in figure 7, ionospheric delays on L1 frequency are several metres, which affect the relative navigation results. Ionospheric delays are larger at noon for the ground station due to the higher insulation.

Furthermore, CODE also provides coefficients of Klobuchar model as follows:

$$
\begin{array}{ll}
\alpha_{0}=1.1277 \times 10^{-8}, & \alpha_{1}=1.2645 \times 10^{-8}, \\
\alpha_{2}=-3.1632 \times 10^{-7}, & \alpha_{3}=5.0342 \times 10^{-7} \\
\beta_{0}=1.1525 \times 10^{5}, & \beta_{1}=-1.7174 \times 10^{4}, \\
\beta_{2}=-8.1250 \times 10^{5}, & \beta_{3}=3.9824 \times 10^{6} .
\end{array}
$$

Ionospheric delays using these coefficients are not exactly the same as those obtained using the coefficients originally broadcast by the GPS for the single-frequency users. Users should choose products from the same organization to reduce errors.

\subsection{Ionospheric corrections using dual-frequency observations}

The Klobuchar model needs to be assessed, especially for spaceborne GPS. Thus, another method should be found to calculate the ionospheric delay. Since both the IGS station and the GRACE satellites are equipped with dual-frequency GPS

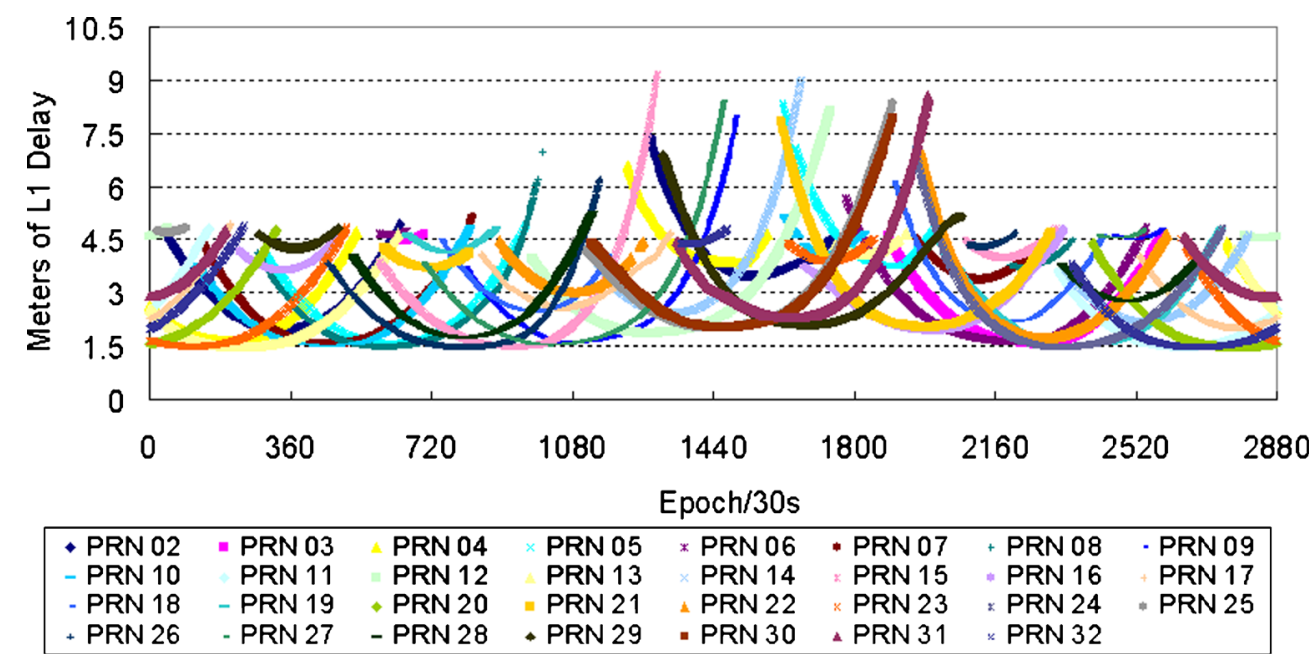

Figure 7. L1 ionospheric delays using Klobuchar model for dlft station on 1 September 2010. 
receivers, it is reasonable to use double frequency observations to validate the Klobuchar model.

GPS pseudorange observation equation can be written as:

$$
\begin{aligned}
P_{i, 1}^{j}= & \rho_{i}^{j}+c\left(d t^{j}-d T_{i}\right)+d_{\text {orb }}^{j}+I_{i, 1}^{j}+T_{i, 1}^{j} \\
& +B_{i, 1}+B_{1}^{j}+M_{i, 1}^{j}+\varepsilon_{i, P_{1}}^{j} \\
P_{i, 2}^{j}= & \rho_{i}^{j}+c\left(d t^{j}-d T_{i}\right)+d_{\text {orb }}^{j}+\gamma I_{i, 1}^{j}+T_{i, 2}^{j} \\
& +B_{i, 2}+B_{2}^{j}+M_{i, 2}^{j}+\varepsilon_{i, P_{2}}^{j}
\end{aligned}
$$

where $i$ stands for receiver; $j$ stands for GPS satellite; $P_{i, 1}^{j}$ and $P_{i, 2}^{j}$ are pseudorange observations, respectively; $\rho_{i}^{j}$ is geometric distance from the satellite to the receiver; $c$ is the speed of light; $d t^{j}$ is the clock error of satellite $j ; d T_{i}$ is the clock error of receiver $i ; d_{\text {orb }}^{j}$ is the satellite orbit error; $I_{i, 1}^{j}$ is the ionospheric delay on L1; $\gamma=\left(f_{1} / f_{2}\right)^{2}$ is the conversion factor related to frequency; $T_{i, 1}^{j}$ and $T_{i, 2}^{j}$ are the tropospheric delays on $\mathrm{P} 1$ and $\mathrm{P} 2$, respectively; $B_{i, 1}$ and $B_{i, 2}$ are the receiver code bias of $\mathrm{P} 1$ and $\mathrm{P} 2$, respectively; $B_{1}^{j}$ and $B_{2}^{j}$ are the satellite code bias of $\mathrm{P} 1$ and $\mathrm{P} 2$, respectively; $M_{i, 1}^{j}$ and $M_{i, 2}^{j}$ are the multi-path effects on $\mathrm{P} 1$ and $\mathrm{P} 2$, respectively; $\varepsilon_{i, P_{1}}^{j}$ and $\varepsilon_{i, P_{2}}^{j}$ are observation noises of P1 and P2, respectively.

Differencing the two formulae we get the following formula:

$$
\begin{gathered}
P_{1}-P_{2}=(1-\gamma) I_{1}+\left(B_{i, 1}-B_{i, 2}\right)+\left(B_{1}^{j}-B_{2}^{j}\right) \\
+\left(M_{1}-M_{2}\right)+\varepsilon_{P_{1}, P_{2}}
\end{gathered}
$$

where $B_{i, 1}-B_{i, 2}$ is the differential receiver code bias of the two frequencies; $B_{1}^{j}-B_{2}^{j}$ is the differential satellite code bias of the two frequencies; $\varepsilon_{P_{1}, P_{2}}$ is the differential noise.
The ionospheric delay on L1, ignoring the multipath errors and noise, is given by:

$$
\begin{array}{r}
I_{1}=\left[\left(P_{1}-P_{2}\right)-\left(B_{i, 1}-B_{i, 2}\right)\right. \\
\left.-\left(B_{1}^{j}-B_{2}^{j}\right)\right] /(1-\gamma) .
\end{array}
$$

We computed ionospheric delays for different GPS satellites using the Klobuchar model and dual-frequency observations, respectively. As shown in figure 8, ionospheric delays calculated using dual-frequency observations are about $4.0-5.5 \mathrm{~m}$ (RMS), while delays achieved by the Klobuchar model are about 2.5-3.5 m (RMS). Comparison shows that the Klobuchar corrections occupied about $60 \%$ (RMS) of the corrections achieved by dual-frequency observations, proving the effectiveness of the Klobuchar model for ground users in middle latitude region.

\subsection{Modified Klobuchar model for spaceborne users}

\subsubsection{Approximate forms of modified Klobuchar model}

As mentioned before, spaceborne GPS receivers are usually above $350 \mathrm{~km}$ altitude, and the single layer height needs to be adjusted to $500 \mathrm{~km}$ for GRACE. Similar to the Klobuchar model for ground users, simplifying assumptions would be made in many cases for spaceborne users to reduce the calculation complexity, with effectiveness of the Klobuchar model preserved.

Since the height of the single layer changes from 350 to $500 \mathrm{~km}$, altitude-related parameters need to be changed. Earth angle between the receiver and the IPP is computed using equation (13).

$$
\psi=90-E_{A}-\arcsin \left(\frac{R}{R+H} \cos E_{A}\right)
$$

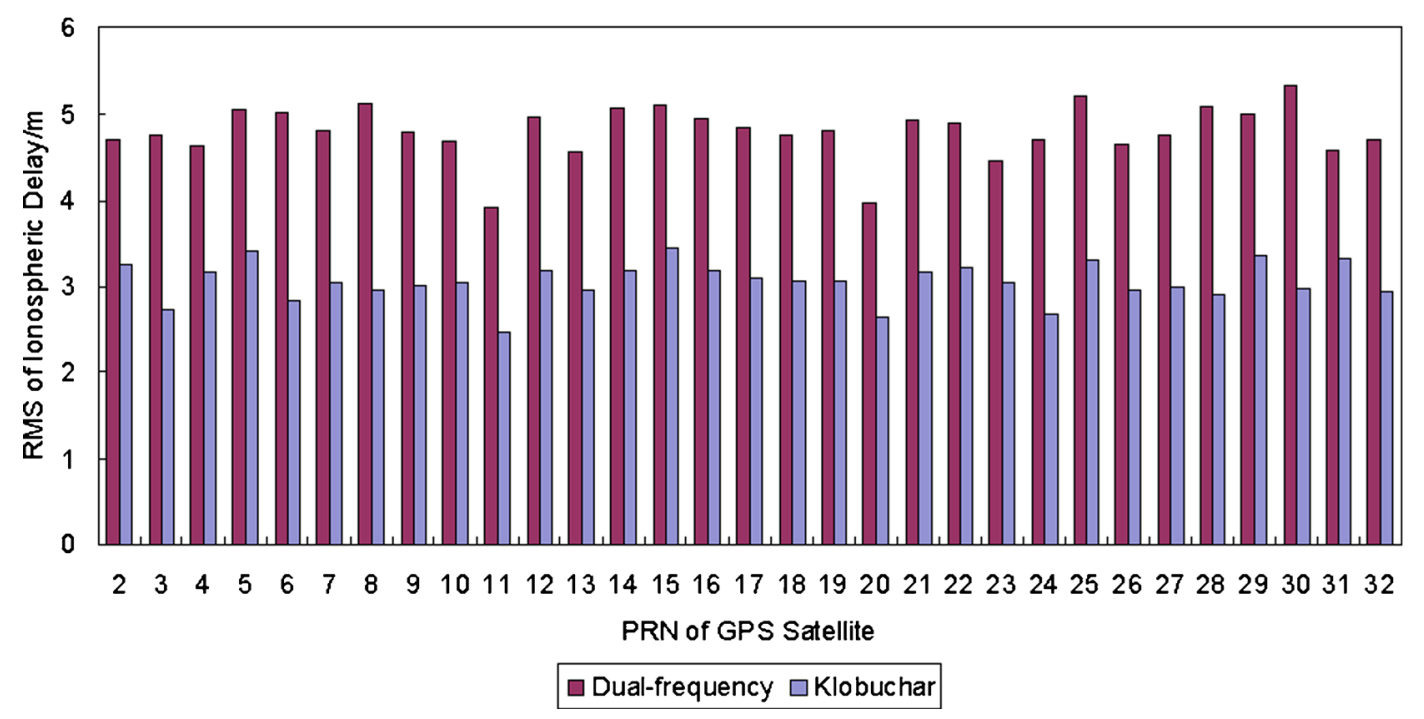

Figure 8. Ionospheric delays using Klobuchar model and dual-frequency observations for dlft station on 1 September 2010. 
where $\psi$ stands for the Earth angle, $E_{A}$ stands for the elevation angle, $R$ is the mean radius of the Earth (considered to be a sphere); $H$ is the height of the single layer above the Earth.

The approximate equation given by Klobuchar (1987) will not be suitable in this case. Instead, we adjust the parameters in Klobuchar's equation to develop a new approximate form for spaceborne GPS users to reduce computational time:

$$
\psi=\frac{700}{E_{A}+25}-6
$$

We computed Earth angle and its approximate value at different heights (figure 9a). The new approximate form is less than $0.2^{\circ}$ in error for all elevation angles greater than $0^{\circ}$ (figure $9 \mathrm{~b}$ ). This precision is almost equal to that of the approximate form developed by Klobuchar for ground GPS users. Thus, the approximation is effective in theory.

Another related parameter is the slant factor (or obliquity factor), which can be defined as the secant of the zenith angle at the mean ionospheric height. As shown in equations (1-3), the mapping function and the slant factor are the same concept. Compared with the slant factor computed by Klobuchar, the modified slant factor and its approximate form were computed (figure 10a). Approximate form for spaceborne GPS users
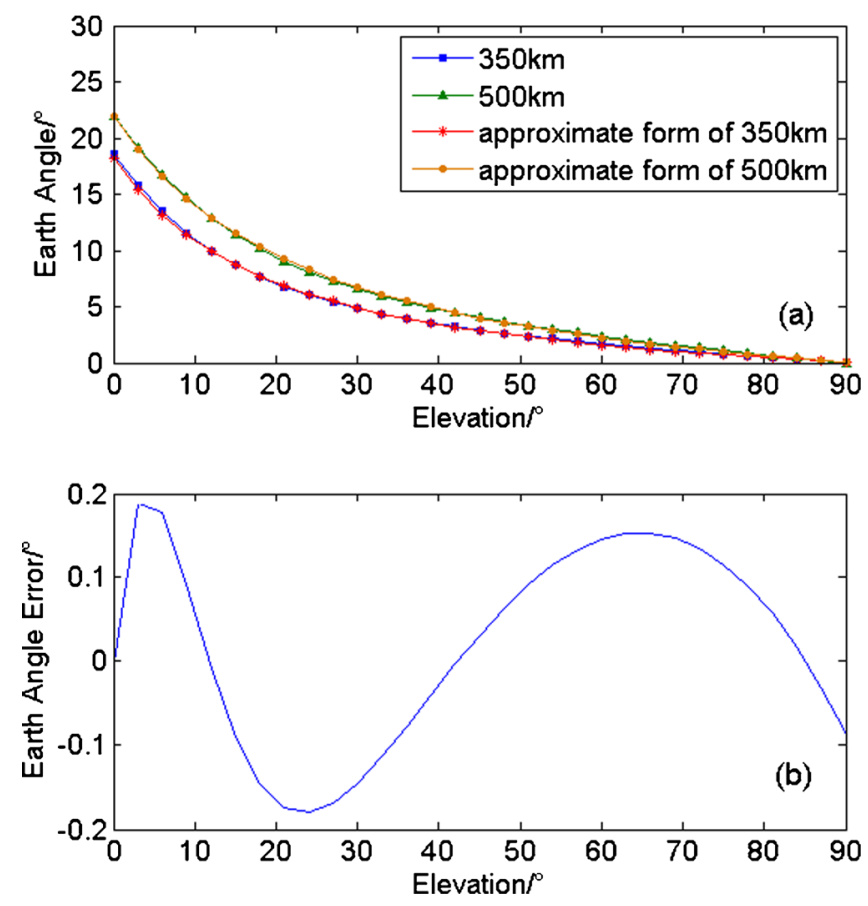

Figure 9. Earth angle (top panel) and Earth angle error (bottom panel) of the new approximate form.
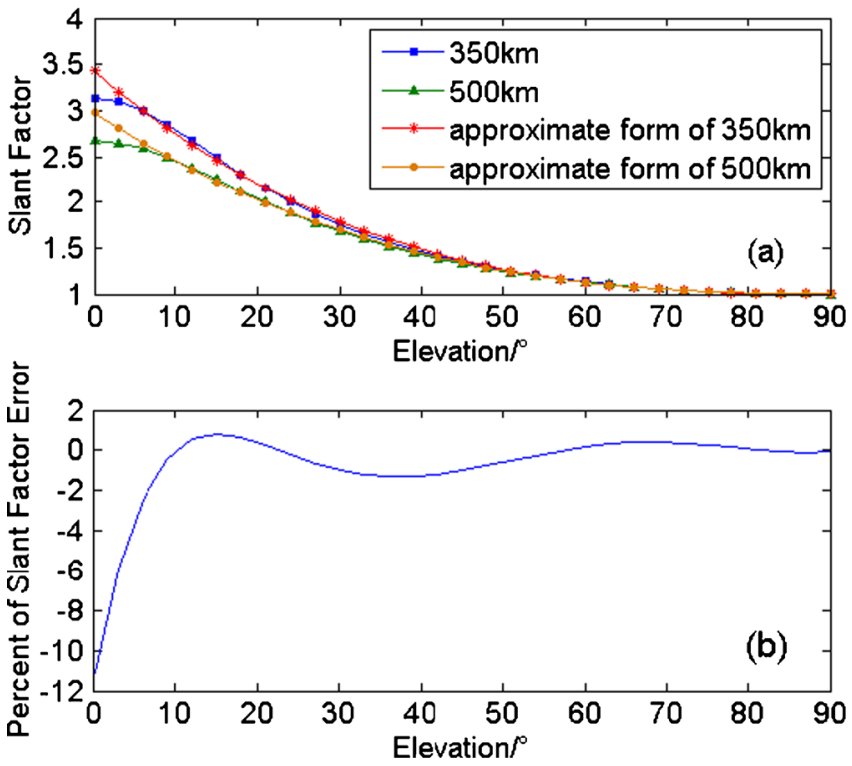

Figure 10. Slant factor (top panel) and percent of slant factor error (bottom panel) of the new approximate form for spaceborne GPS users.

(equation 15) substitutes the approximation given by Klobuchar for ground users.

$$
F_{I}(z)=1+1.7\left(\frac{95-E_{A}}{90}\right)^{2.75}
$$

The new approximate form is within $2 \%$ of the exact value for all elevation angles greater than $7^{\circ}$ (figure 10b). This precision is a little worse than that of the approximate form developed by Klobuchar for ground GPS users, but still is acceptable in theory.

\subsubsection{Ionospheric correction using modified Klobuchar model}

Quite similar to the Klobuchar model for ground users (Klobuchar 1987), the calculation scheme of modified Klobuchar model is as follows:

1) Calculate the Earth angle $\psi$ using equation (14).

2) Calculate the subionospheric latitude:

$$
\Phi_{I}=\Phi_{u}+\psi \cos A
$$

where $\Phi_{u}$ is the user approximate geodetic latitude, $A$ is the azimuth. If $\Phi_{I}>0.416$, then $\Phi_{I}=0.416$. If $\Phi_{I}<-0.416$, then $\Phi_{I}=-0.416$.

3) Compute the subionospheric longitude:

$$
\lambda_{I}=\lambda_{u}+\frac{\psi \sin A}{\cos \Phi_{I}}
$$

where $\lambda_{u}$ is the user approximate geodetic longitude. 
4) Compute the geomagnetic latitude:

$$
\Phi_{m}=\Phi_{I}+0.064 \cos \left(\lambda_{I}-1.617\right)
$$

5) Compute the local time:

$$
t=4.32 \times 10^{4} \lambda_{I}+t_{\mathrm{GPS}}
$$

where $t_{\text {GPS }}$ stands for the GPS time in second. If $t>86,400$, then $t=t-86,400$. If $t<0$, then $t=t+86,400$.

6) Compute the slant factor using equation (15).

7) Compute the ionospheric time delays using equation (9).

Note: The units of angle and time are semi-circle and second, respectively. $T_{\mathrm{IONO}}$ is referred to the
L1 frequency. If users require the ionospheric delay on the L2 frequency, the correction term should be multiplied by the constant 1.65.

Ionospheric delays were calculated using the above scheme (figure 11). Compared with ionospheric delays for ground GPS users, whose peak appears at noon due to the higher insulation, ionospheric delays for spaceborne GPS users show strong periodicity. As shown in figure 11, there are about 16 periods with 16 peaks during one day, since the period of GRACE is about $90 \mathrm{~min}$ and the satellite runs 16 cycles around the Earth during one day. This periodic phenomenon is similar to the results obtained by Garcia-Fernàndez and Montenbruck (2006) for VTEC above the CHAMP satellite whose period is also about $90 \mathrm{~min}$.

As mentioned in section 3.1, only the ionosphere above the altitude of GRACE will influence the

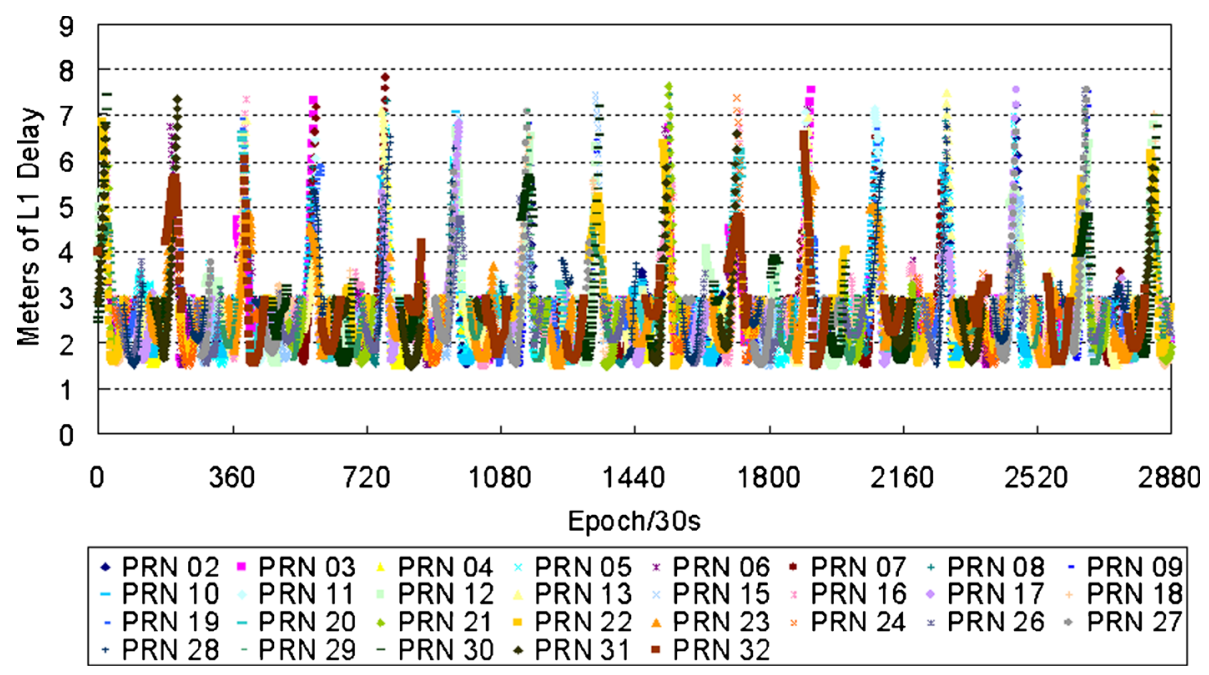

Figure 11. L1 ionospheric delays using modified Klobuchar model for spaceborne GPS on 1 September 2010.

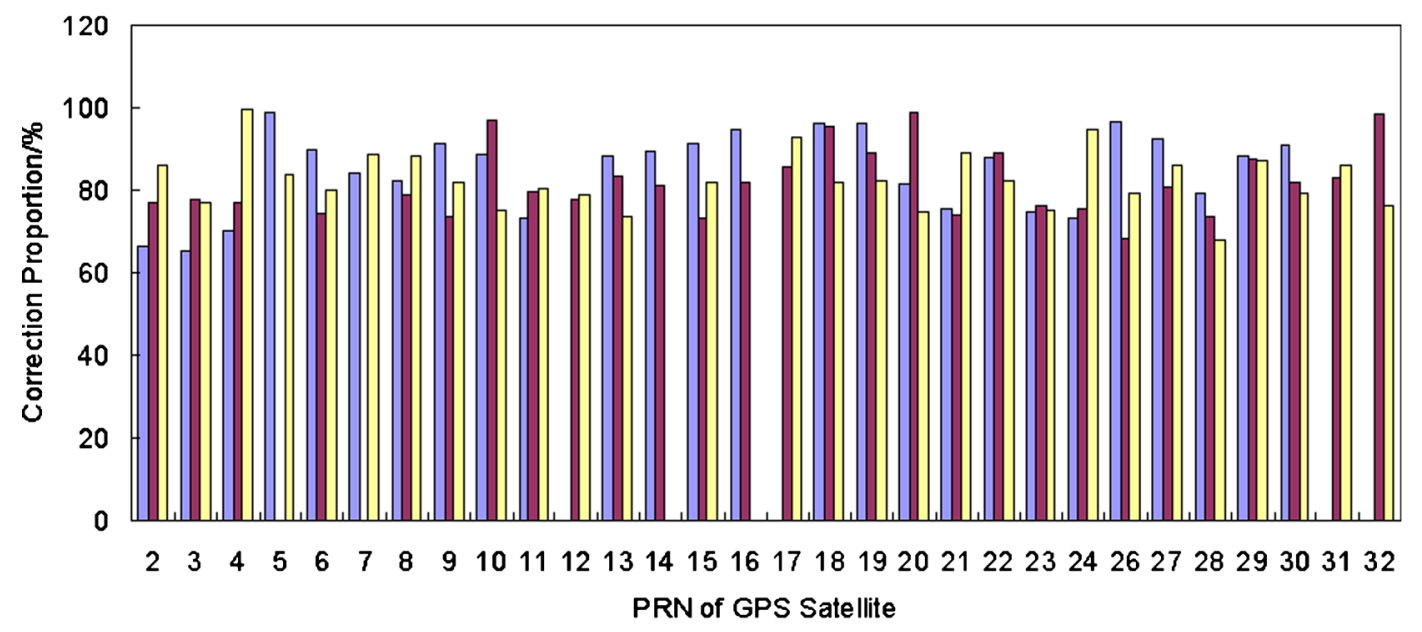

$\square 2006.01 .01 \square 2008.09 .01 \square 2010.09 .01$

Figure 12. Correction proportion using modified Klobuchar model on different days. 
GPS signal, causing less path delays than on the ground. An altitude-dependent scale factor (Montenbruck and Gill 2002) should be multiplied to the ionospheric delays achieved by the modified Klobuchar model. The scale factor for GRACE needs to be adjusted in the processing of different data set to avoid producing more harm than benefit.

Ionospheric delays for spaceborne GPS were calculated using new approximate forms developed in this study, compared with ionospheric delays calculated by dual-frequency observations. Data from three days of different years were processed and the corresponding RMS values were computed. As shown in figure 12, ionospheric delays of the selected datasets calculated using the modified Klobuchar model are more than 60\% (RMS) of those calculated by dual-frequency observations. The average proportion of these corrections is more than $80 \%$ (RMS) (table 1).

Results show that the proposed ionospheric correction method is applicable to the selected data sets. However, it should be further discussed for more datasets and more LEO satellites in the future. Moreover, since most of the plasma in Earth's ionosphere is located below $500 \mathrm{~km}$, the impact of ionosphere on the spaceborne GPS users parked above $500 \mathrm{~km}$ would be minimal and the required ionospheric corrections may be of academic interest only. Nevertheless, the ionospheric model to be used for a single frequency user located above F-region peak of the ionosphere is worth having a serious discussion.

Table 1. Scale factor and average correction proportion using modified Klobuchar model.

\begin{tabular}{lccc}
\hline Date & $01 / 01 / 2006$ & $01 / 09 / 2008$ & $01 / 09 / 2010$ \\
\hline Scale factor & 0.42 & 0.30 & 0.34 \\
Correction proportion & $85 \%$ & $82 \%$ & $83 \%$ \\
\hline
\end{tabular}

\subsubsection{Relative positioning with ionospheric corrections}

The impact of fractional ionosphere above the GRACE altitude is not quite large, but still will affect the precise positioning or orbit determination. The relative position solutions were obtained using Kalman filter with the corrections of ionospheric delays proposed in this study, compared with JPL solution for GRACE on 1 September 2010. As shown in figure 13, positioning accuracy is in decimetre level after convergence of filter, and can be up to centimetre or millimetre level finally. Results and analysis demonstrate the overall validity of the proposed ionospheric correction method for GRACE.

The proposed method is especially meaningful for single-frequency GPS users located below $500 \mathrm{~km}$, since a spaceborne single-frequency receiver is much simpler and cheaper than a dual-frequency one. Furthermore, this method is applicable to dual-frequency users who use double difference combinations of L1 and do not require high precision. Since impact of the fractional ionosphere on spaceborne GPS is smaller but more complicated, it should be discussed more deeply in the future.

\section{Conclusions}

SLM mapping function applicable to spaceborne GPS was analyzed. Klobuchar models for ground and spaceborne GPS were presented, respectively. New approximate equation of Earth angle for the modified Klobuchar model was proposed, and approximate form of slant factor was given. Ionospheric delays of the dlft station and the GRACE satellite were calculated using the Klobuchar model and the modified Klobuchar model proposed in this

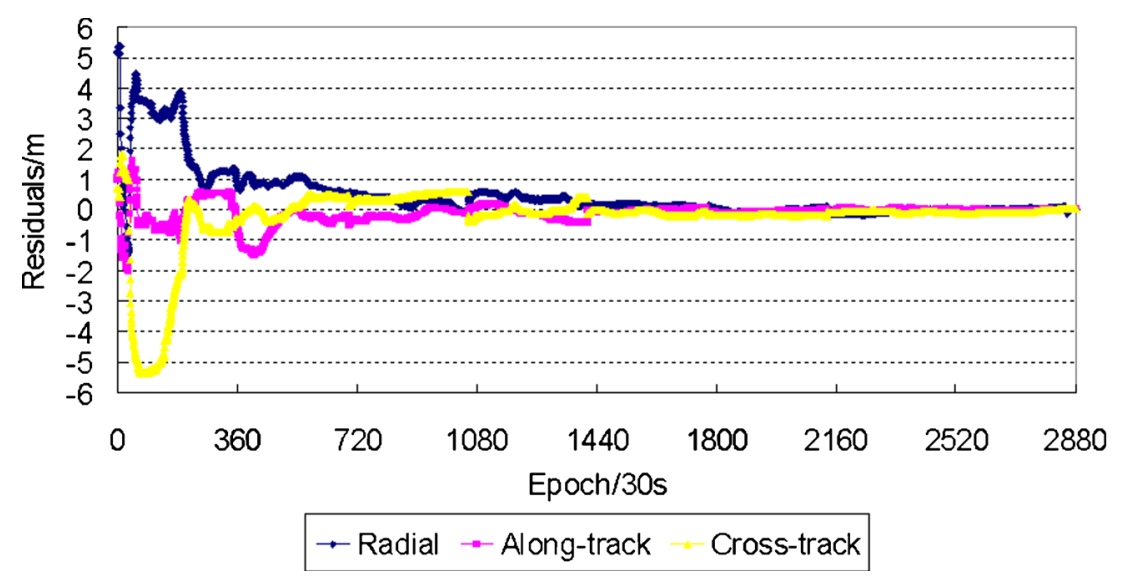

Figure 13. Residuals of GRACE relative position solution compared with JPL solution on 1 September 2010. 
paper, respectively. The following conclusions can be drawn in this study:

- The single layer height needs to be changed according to the altitudes of spacecrafts. Single layer height of $500 \mathrm{~km}$ is applicable to spaceborne GPS for GRACE.

- The approximation error of Earth angle developed in this research is no more than $0.2^{\circ}$ for satellites above $0^{\circ}$ elevation.

- New approximate form of slant factor is within $2 \%$ of the exact value for all elevation angles greater than $7^{\circ}$.

- The Klobuchar model works well for ground GPS, which can be verified by dual-frequency results. The modified Klobuchar model with scale factors corrects about $80 \%$ on average of the ionospheric delays for the selected datasets, which are beneficial to single-frequency spaceborne GPS users but need to be tested more in further study.

- The relative positioning accuracy can be up to centimetre or millimetre level after the convergence of Kalman filter with the correction of ionospheric delays proposed in this study, compared with JPL solution for GRACE on 1 September 2010.

\section{Acknowledgements}

This work was developed with financial support of the National Natural Science Foundation of China, Major International (Regional) Joint Research Program of China (Grant No. 41210006). Data employed in the analysis were obtained from SOPAC, CDDIS, CODE and GFZ websites.

\section{References}

Angrisano A, Gaglione S and Gioia C et al. 2011 Ionospheric models comparison for single-frequency GNSS positioning; ENC 2011.

Bent R B, Llewellyn S K and Schmid P E 1972a A highly successful empirical model for the worldwide ionospheric electron density profile; DBA Systems, Melbourne, Florida.

Bent R B, Llewellyn S K and Walloch M K 1972b Description and evaluation of the Bent Ionospheric Model; DBA Systems, Melbourne, Florida.

Bilitza D 1986 International reference ionosphere - recent developments; Radio Sci. 21(3) 343-346.

Bilitza D 2001 International reference ionosphere 2000; Radio Sci. 36(2) 261-275.

Bilitza D and Reinisch B W 2008 International reference ionosphere 2007: Improvements and new parameters; $A d v$. Space Res. 42(4) 599-609.

Bilitza D, McKinnell L A and Reinisch B et al. 2011 The international reference ionosphere today and in the future; J. Geodesy 85(12) 909-920.
Daniell R E Jr, Brown L D, Anderson D N, Fox M W, Doherty P H, Decker D T, Sojka J J and Schunk R W 1995 Parameterized ionospheric model: A global ionospheric parameterization based on first principles models; Radio Sci. 30(5) 1499-1510.

Dach R, Hugentobler U, Fridez P and Meindl M (eds) 2007 Bernese GPS Software Version 5.0; Astronomical Institute, University of Bern.

Ebinuma T, Bishop R H and Lightsey E G 2003 Integrated hardware investigations of precision spacecraft rendezvous using the global positioning system; J. Guid. Control Dynam. 26(3) 425-433.

Garcia-Fernàndez M and Montenbruck O 2006 Low Earth orbit satellite navigation errors and vertical total electron content in single-frequency GPS tracking; Radio Sci. 41(5).

GRACE Orbital Configuration 2010 http://www.csr.utexas. edu/grace/operations/configuration.html.

IGS 2006 International GPS Service; http://igscb.jpl.nasa. gov.

Klobuchar J A 1975 A First-Order, Worldwide, Ionospheric, Time-Delay Algorithm; Air Force Surveys in Geophys. No. 324.

Klobuchar J A 1986 Design and characteristics of the GPS ionospheric time delay algorithm for single frequency users; Proceedings of PLANS '86, Las Vegas, NV, pp. 280-286.

Klobuchar J A 1987 Ionospheric time-delay algorithm for single-frequency GPS users; IEEE Transactions on Aerospace Electronic Systems 23(3) 325-331.

Klobuchar J A 1996 Ionospheric effects on GPS; Global Positioning System: Theory Appl. I 485-516.

Komjathy A and Langley R B 1996 The effect of shell height on high precision ionospheric modelling using GPS; Proceedings of the 1996 IGS Workshop International GPS Service for Geodynamics (IGS), pp. 193-203.

Kroes R 2006 Precise relative positioning of formation flying spacecraft using GPS; PhD thesis, TU Delft, The Netherlands.

Leung S and Montenbruck O 2005 Real-time navigation of formation-flying spacecraft using global-positioningsystem measurements; J. Guid. Control Dynam. 28(2) 226-235.

Li W P, LI J W and Dai W 2009 Study on the methods of updating Klobuchar ionospheric delay correction model; Science Surveying and Mapping (in Chinese) 34(5) 49-51.

Montenbruck O and Gill E 2002 Ionospheric correction for GPS tracking of LEO satellites; The J. Navigation $\mathbf{5 5}$ 293-304.

Mannucci A J, Wilson B D and Yuan D N et al. 1998 A global mapping technique for GPS derived ionospheric total electron content measurements; Radio Sci. 33(3) $565-582$.

Orús R, Hernández-Pajares M and Juan J M et al. 2002 Performance of different TEC models to provide GPS ionospheric corrections; J. Atmos. Sol.-Terrest. Phys. 64(18) 2055-2062.

Rawer K, Bilitza D and Ramakrishnan S 1978 Goals and status of international reference ionosphere; Rev. Geophys. 16(2) 177-181.

Schaer S, Gurtner W and Feltens J 1998 IONEX: The IONosphere Map Exchange Format Version 1; Proceedings of the 1998 IGS Analysis Centers Workshop, ESOC, Darmstadt, Germany, February 9-11.

Schaer S 1999 Mapping and predicting the Earth's ionosphere using the global positioning system; Vol. 59, Geodätisch-geophysikalische Arbeiten in der Schweiz, Schweizerischen Geodätischen Kommission, Institut 
für Geodäsie und Photogrammetrie, Eidg. Technische Hochschule Zürich, Zürich, Switzerland.

Tancredi U, Renga A and Grassi M 2011 Ionospheric path delay models for spaceborne GPS receivers flying in formation with large baselines; Adv. Space Res. 48 507-520.

Wen J, Wan W X and Ding F et al. 2010 Expermential observation and statistical analysis of the vertical TEC mapping function; Chinese J. Geophys. (in Chinese) 53(1) 22-29.

Xu G 2007 GPS Theory, Algorithms and Applications; Springer.

Yuan Y B, Huo X L and Ou J K et al. 2008 Refining the Klobuchar ionospheric coefficients based on GPS observation; IEEE Transactions on Aerospace and Electronic Systems 44(4) 1498-1510.

Yunck T P, Bertiger W I and Wu S C et al. 1994 First assessment of GPS-based reduced dynamic orbit determination on TOPEX/Poseidon; Geophys Res. Let. 21(7) $541-544$.

Zhao J X 2003 The study on mathematical model of high dynamic and intelligent GPS satellite signal simulator's software; PhD thesis, Beijing University of Aeronautics and Astronautics, Beijing, China (in Chinese).

Zhao J X, Cheng Q and Zhang Q S et al. 2003 Research of ionospheric time-delay error simulation in high dynamic GPS signal simulator; Chinese J. Aeronautics 16(3) 169-176. 